\title{
Obstetric and neonatal outcomes of the pregnancies complicated with thrombocytopenia
}

\author{
Pratima Kumari, Saurabh V. Bhangale*, Asmita N. Patil
}

Department of Obstetrics and Gynecology, Rajiv Gandhi Medical college and Chatrapati Shivaji Maharaj hospital, Kalawa, Thane, Maharashtra, India

Received: 08 February 2019

Revised: 14 September 2019

Accepted: 30 September 2019

\section{*Correspondence:}

Dr. Saurabh V. Bhangale,

E-mail: dr.saurabh.v.bhangale@gmail.com

Copyright: () the author(s), publisher and licensee Medip Academy. This is an open-access article distributed under the terms of the Creative Commons Attribution Non-Commercial License, which permits unrestricted non-commercial use, distribution, and reproduction in any medium, provided the original work is properly cited.

\section{ABSTRACT}

Background: Thrombocytopenia is second most common hematological abnormality in pregnancy after anemia (Incidence 8-10\%). The aim of this study is to observe the obstetric and neonatal outcomes of pregnancies complicated with thrombocytopenia and to compare its maternal and fetal outcomes.

Methods: The prospective observational study was conducted at tertiary care institute over period of one and half year and 100 cases of thrombocytopenia in present pregnancy were included after fulfilling inclusion and exclusion criteria and obtaining written informed valid consent. Complete history, physical examination and relevant investigations of the patient were documented. Patients were followed up to delivery and outcomes (obstetric, maternal, fetal, neonatal) were studied. The data obtained for all the patients was analyzed with SPSS (SPSS Inc, Chicago) software packages. Statistical comparisons were performed with Pearson's Chi- square where appropriate with p-value of $<0.05$ considered statistically significant.

Results: Most common cause of thrombocytopenia in pregnancy was gestational thrombocytopenia in (25\%) cases followed by preeclampsia (20\%). Most cases (94\%) were diagnosed in antepartum period out of which most (58\%) at $>37$ weeks of gestation. Most (53\%) had moderate thrombocytopenia. Incidence of maternal complications was statically significant (P-value 0.038) with most common complication being caesarian section site oozing (9\%) followed by placental abruption (4\%). There was no statistical significance in degree of thrombocytopenia and need for blood and blood product transfusion (P-value 0.67$)$. Only (2\%) neonates of thrombocytopenic mothers had thrombocytopenia and both required treatment.

Conclusions: Most common cause of thrombocytopenia in pregnancy was gestational thrombocytopenia with uneventful pregnancy and perinatal outcomes. Few severe cases associated with medical or systematic causes leads to serious catastrophic events which can be avoided by increasing antenatal surveillance and appropriate management by multidisciplinary team of obstetrician, hematologist, anesthesiologist, neonatologist and physician.

Keywords: Fetal outcome, Maternal outcome, Neonatal outcome, Pregnancy, Thrombocytopenia

\section{INTRODUCTION}

Pregnancy is a physiological state which is associated with alternations in metabolic and biochemical processes.
Normal serum platelet count in pregnancy is $1.5-4$ lakh/ $\mu 1$. Pregnancy causes a physiological fall in the platelet count associated with a leftward shift in the platelet count distribution. 
Low platelet counts can be due to:

- An increase in consumption or destruction or rarely due to less production of platelets.

- Due to hemodilution of plasma volume platelet count decrease by approximately $6 \%-7 \%$ during $3 \mathrm{rd}$ trimester. ${ }^{1}$

However, in most of the patients the absolute platelet count remains within normal range. ${ }^{1-4}$

Thrombocytopenia is the $2^{\text {nd }}$ most common hematological finding in pregnancy after anemia. ${ }^{5}$ The overall incidence of thrombocytopenia in pregnancy is approximately $8-10 \%$ but when patients with obstetric or medical conditions are excluded, then the incidence drops to $5.1 \% .^{5}$ A drop in platelet count below $150,000 / \mu \mathrm{L}$ is defined as thrombocytopenia. Thrombocytopenia may be• Mild - 100,000-150,000/ $\mu \mathrm{L}$, - Moderate - 50,000$100,000 / \mu \mathrm{L}, \cdot$ Severe $-50,000 / \mu \mathrm{L}{ }^{6}{ }^{6}$ Any pregnant patient with platelet count below $100,000 / \mu \mathrm{L}$ requires further clinical and laboratory assessment.

Pregnancy is associated with physiological changes in platelet count, but there are many pathological conditions which are associated with thrombocytopenia and can have a significant impact on the mother and the baby. There are diverse etiologies of thrombocytopenia in pregnancy out of which some are unique to pregnancy (Table 1$)^{7}$

Table 1: Etiology of thrombocytopenia in pregnancy. ${ }^{7}$

\begin{tabular}{|c|c|c|}
\hline & Pregnancy specific & Not pregnancy specific \\
\hline $\begin{array}{l}\text { Isolated } \\
\text { thrombocytopenia }\end{array}$ & $\begin{array}{l}\text { Gestational thrombocytopenia } \\
(70-80 \%)\end{array}$ & $\begin{array}{l}\text { Primary ITP }(1-4 \%) \\
\text { Secondary ITP }(<1 \%)^{*} \\
\text { Drug induced thrombocytopenia** } \\
\text { Congenital thrombocytopenia** } \\
\text { Type } 2 \text { B von Willebrand disease** }\end{array}$ \\
\hline $\begin{array}{l}\text { Thrombocytopenia } \\
\text { associated with } \\
\text { systemic disorders }\end{array}$ & $\begin{array}{l}\text { Severe preeclampsia }(15-20 \%) \\
\text { HELLP syndrome }(<1 \%) \\
\text { Acute fatty liver of pregnancy }(<1 \%)\end{array}$ & $\begin{array}{l}\text { Thrombotic thrombocytopenic purpura } \\
\text { /Hemolytic uremic syndrome } \\
\text { Systemic lupus erythromatosus** } \\
\text { Anti-phospholipid antibody syndrome }{ }^{* *} \\
\text { Viral infections** } \\
\text { Bone marrow disorders** } \\
\text { Nutritional deficiency** } \\
\text { Thyroid disorders** } \\
\text { Splenic sequestration (liver diseases, portal } \\
\text { vein thrombosis etc.) }{ }^{* *}\end{array}$ \\
\hline
\end{tabular}

Approximately $75 \%$ of these cases are due to gestational thrombocytopenia; $15-20 \%$ can be due to hypertensive disorders; $3-4 \%$ to an immune process and the remaining $1-2 \%$ are made up of rare constitutional thrombocytopenia, infections and hematological malignancies. ${ }^{6}$ Thrombocytopenia in the obstetric patient may be due to benign disorders such as incidental gestational thrombocytopenia to life-threatening syndromes such as the 'hemolysis, elevated liver enzymes, low platelets' syndrome (HELLP). ${ }^{1}$

Most of the cases of thrombocytopenia are mild and have no significant effect on mother or fetus but in those cases where thrombocytopenia is a part of a complex clinical disorder like HELLP (hemolysis, elevated liver enzymes and low platelets) syndrome it can be profound and can lead to life-threatening results in both mother and baby.

Bleeding during surgery is uncommon unless the platelet counts are less than 50,000/microliter. Clinically significant spontaneous bleeding occurs when platelet counts fall below $10,000 / \mu \mathrm{L}$. Pregnant women with thrombocytopenia have high risk of bleeding during and after childbirth especially if caesarean section or other surgical intervention has done during pregnancy, labor, and puerperium. Such bleeding complications are more likely when platelet count is less than $50,000 / \mu \mathrm{L} .{ }^{8}$

A multidisciplinary team approach involving obstetrician, hematologists, paediatricians, physician, neonatologist and anaesthetists is required for the optimal management of pregnant women with thrombocytopenia.

Screening of pregnant women who are at high risk and preventing its recurrences are the key issues in the management of thrombocytopenia in pregnancy, hence early diagnosis and identification of complications due to thrombocytopenia and timely management are the main strategy of treatment.

The aim of this study was to observe the obstetric and neonatal outcomes of pregnancies complicated with 
thrombocytopenia and to compare its maternal and fetal outcomes. The main objective of our study was to find out the proportion of thrombocytopenia in pregnancy in study subjects and to compare the thrombocytopenia of pregnancy with pregnancy complications and also to study maternal and fetal outcome.

\section{METHODS}

A prospective observational study was conducted in the Department of Obstetrics and Gynecology in tertiary care centre.

\section{Inclusion criteria}

- Patients who were diagnosed of thrombocytopenia, on the basis of blood investigations and clinical picture, were included

- All types of thrombocytopenia were included. Patients who delivered at our tertiary care centre with thrombocytopenia were included. Irrespective of registration status all patients with thrombocytopenia were included (patients who were referred to the institution only at the time delivery /termination of pregnancy and those who were registered antenatally with the institute were included)

- Patients were included irrespective of the parity status

- Patients in third trimester with thrombocytopenia were included.

\section{Exclusion criteria}

- Patient unwilling to give informed consent were excluded.

The method used to calculate the sample size was universal sampling. Deliveries in our institute every year is around 10000-12000. Incidence of thrombocytopenia in pregnancy is $7 \% .{ }^{5}$ Hence, sample size is 100 .

\section{Methodology}

- Patients delivering/undergoing completion of pregnancy in our institute were enrolled

- Patients fulfilling inclusion criteria were enrolled into the study, after valid consent was taken

- In case of semi-conscious or unconscious patients, written informed consent was signed by the relatives

- Complete history, physical examination and relevant investigations of the patient were documented

- Patients were followed up to delivery and outcomes were studied till the patients were discharged.

\section{The following parameters were studied}

- Blood investigation: review complete blood count $(\mathrm{CBC})$ at the time of admission
- Determine bleeding history, co-morbidities, platelet count pre-natally and in previous pregnancies

- Review blood film - fragmentation, platelet size, for malaria parasite

- Blood pressure, urinalysis, protein: creatinine ratio, electrolytes, urea, creatinine (UEC), liver function test, uric acid to exclude pre-eclampsia or related syndrome

- Risk of bleeding assessed

- Hematology reference for moderate to severe thrombocytopenia (platelet $<100 \times 109 / \mathrm{L}$ ), with known history of idiopathic thrombocytopenic purpura (ITP) or previous severe thrombocytopenia

- Monitored Full blood count regularly

- Arrange antenatal anesthetic consult if platelet count $<1.0 \mathrm{lakh} / \mu 1$

- Complete blood count on admission, in labour and at the time of discharge

- Complications-Maternal outcome - Placental abruption, petechial rashes, epitasis, episiotomy hematoma, postpartum hemorrhage, caesarean section site oozing, wound hematoma, hemoperitoneum, intracranial bleeding, gastrointestinal bleeding, medicine intensive care unit admission and maternal mortality. Neonatal outcome- stillbirth, intrauterine growth restriction, birth asphyxia, meconium aspiration syndrome, early thrombocytopenia, generalized petechiae, cephalhematoma, visceral and intracranial hemorrhage, perinatal mortality

- Requirement of transfusion of blood or blood products to the mother and neonates

- Longevity of gestation - full term /pre-term

- $\quad$ Type of delivery - normal vaginal / LSCS / forceps / vacuum.

- Neonatal outcomes: birth weight / bleeding manifestations / Apgar score / NICU admission / Neonatal death / intrauterine fetal demise. Gestational age was determined by the last menstrual period, uterine size at the first prenatal visit or early sonography if obtained.

Intrauterine growth restriction was defined as birth weight below the $10^{\text {th }}$ percentile for that gestational age.

Appropriate management was done according to case and was documented in brief.

- General nursing care, strict blood pressure monitoring, strict input output charting (by indwelling catheter in eclampsia), maternal and perinatal risk counseling, maintaining hydration and monitoring of vital parameters.

- Antihypertensive: Tab Nifedipine $10 \mathrm{mg}$ or tab Alphamethyldopa $500 \mathrm{mg}$ orally used if blood pressure is $>140 / 100$. Prophylactic magnesium Sulphate with Pritchard's regimen in severe preeclampsia with impending signs of eclampsia 
- Blood and blood products were used to correct coagulation abnormalities and anemia

- Inj. Dexamethasone $6 \mathrm{mg}$ intramuscular 2 times daily for 2 days in preterm patients

- Obstetrics management: Once the patient was stabilized, Bishop's score was assessed by per vaginal examination. Hematologist reference was taken. Mode of induction was decided depending upon the period of gestation, favorability of cervix and the urgency for induction. If cervix was favorable, labour was accelerated with ARM and oxytocin infusion. If cervix was unfavorable, cervical ripening was done with PGE2 (Dinoprostone gel) after obtaining the consent from the patient and the relatives. Caesarean section was done for obstetrics indication or worsening parameters. Platelets transfused after taking hematologist reference. All the women and the new-born were followed and monitored for 1 week in the post-partum period or till there hospital stay.

Major maternal complications like (Placental abruption, petechial rashes, epitasis, episiotomy hematoma, postpartum hemorrhage, caesarean section site oozing, wound hematoma, hemo-peritoneum, intracranial bleeding, gastrointestinal bleeding, medicine intensive care unit admission and maternal mortality) and associated morbidity were looked for and analyzed. Outcomes were measured in terms of age of mother, parity, antenatal status, duration of gestation, any history of bleeding manifestation in this or in previous pregnancy, blood pressure, platelets count at the time of admission/labour/discharge, laboratory findings, mode of delivery, any intraoperative or postoperative complications, need for platelet transfusion, need for blood or other product transfusions, need for medicine intensive care unit admission for mother, final maternal outcome, neonatal outcome (birth weight, APGAR score, platelet count on day 2 of birth, any complication, need for platelet transfusion, need for NICU admission, final outcome).

\section{Statistical analysis}

The data obtained for all the patients with mild, moderate, severe thrombocytopenia has been tabulated and analyzed systematically. The Excel and SPSS (SPSS Inc, Chicago) software packages were used for data entry and analysis. The results were averaged (Mean \pm SD) for each parameter for continuous data and number and percentage for categorical values presented in tables and figures. Statistical comparisons were performed with Pearson's Chi- square where appropriate with p-value of $<0.05$ considered statistically significant.

\section{RESULTS}

Mean maternal age in our study was 26.87 year (19-45 years). Majority, of patients (46\%) belonged to age group up to 25 years of age (Table 2).
Table 2: Distribution of study group on basis of age.

\begin{tabular}{|lll|}
\hline Age group & $\mathbf{N}$ & $\%$ \\
\hline$<25$ years & 46 & 46 \\
\hline $26-30$ years & 36 & 36 \\
\hline$>30$ years & 18 & 18 \\
\hline Total & 100 & 100 \\
\hline
\end{tabular}

$50(50 \%)$ cases were registered with the institute whereas $50(50 \%)$ patients were referred to the institute for further management, it being a tertiary care centre.

Majority of the patients $66(66 \%)$ were multigravida and $34(34 \%)$ were primigravida.

Majority $58(58 \%)$ of the patients presented at more than 37 weeks of gestation and $42(42 \%)$ patients presented at gestational age in between 30 weeks to 36.6 weeks.

Majority 94 (94\%) of the patients of thrombocytopenia in pregnancy were diagnosed in antepartum period followed by $6(6 \%)$ patients who presented with thrombocytopenia in intra-partum period. None, cases were diagnosed in post-partum period (Table 3 ).

Table 3: Distribution of study group as per the time of diagnosis of thrombocytopenia.

\begin{tabular}{|lll|}
\hline Time of diagnosis & $\mathbf{N}$ & $\%$ \\
\hline Antepartum & 94 & 94 \\
\hline Intrapartum & 6 & 6 \\
\hline Postpartum & 0 & 0 \\
\hline Total & $\mathbf{1 0 0}$ & $\mathbf{1 0 0}$ \\
\hline
\end{tabular}

Among study population, majority 25 (25\%) of patients were diagnosed as gestational thrombocytopenia, followed by $20(20 \%)$ of patients were pre-eclamptics. Other causes of thrombocytopenia in pregnancy were 14 (14\%) dengue NS1 positive, $8(8 \%)$ haemolysis elevated liver enzymes low platelets (HELLP) syndrome, $6(6 \%)$ immune thrombocytopenia purpura (ITP), 5 (5\%) eclampsia, 4 (4\%) complicated malaria, 7 (7\%) liver disease in pregnancy and $11(11 \%)$ were others which includes disseminated intravascular coagulation (DIC), aplastic anemia, chronic hypertension (Table 4).

Majority $53(53 \%)$ of the patients had moderate thrombocytopenia (0.5-1 lakh/ $\mu \mathrm{L})$, followed by $33(33 \%)$ had mild thrombocytopenia (1-1.5 lakh/ $\mu \mathrm{L})$ and $14(14 \%)$ patients had severe thrombocytopenia $(<0.5$ lakh/ $\mu \mathrm{L})$ (Table 5).

Majority 38 (38\%) of the patients had full term normal vaginal delivery (FTND) followed by 34 (34\%) of the patients had pre-term vaginal delivery (PTVD), 25 (25\%) of the patients required caesarean sections (LSCS) and 3 (3\%) required instrumental deliveries (Table 6). 
Table 4: Distribution of study group as per the cause of thrombocytopenia.

\begin{tabular}{|lll|}
\hline Cause of thrombocytopenia & N & $\%$ \\
\hline Gestational thrombocytopenia & 25 & 25 \\
\hline Preeclampsia & 20 & 20 \\
\hline Eclampsia & 5 & 5 \\
\hline HELLP syndrome & 8 & 8 \\
\hline Dengue NS1 positive & 14 & 14 \\
\hline Complicated malaria & 4 & 4 \\
\hline ITP & 6 & 6 \\
\hline Liver disease in pregnancy & 7 & 7 \\
\hline $\begin{array}{l}\text { Other (DIC, aplastic anemia, chronic } \\
\text { hypertension) }\end{array}$ & 11 & 11 \\
\hline Total & 100 & 100 \\
\hline
\end{tabular}

Table 5: Distribution of study group as per the classification of thrombocytopenia.

\begin{tabular}{|lll|}
\hline $\begin{array}{l}\text { Thrombocytopenia classification } \\
\text { (platelet count/uL) }\end{array}$ & N & $\%$ \\
\hline Mild $(1,00,000-1,50,000)$ & 33 & 33 \\
\hline Moderate $(50,000-1,00,000)$ & 53 & 53 \\
\hline Severe $(<50,000)$ & 14 & 14 \\
\hline Total & 100 & 100 \\
\hline
\end{tabular}

Table 6: Distribution of study group as per mode of delivery.

\begin{tabular}{|ll|l|}
\hline Mode of delivery & N & $\%$ \\
\hline FTND & 38 & 38 \\
\hline PTVD & 34 & 34 \\
\hline LSCS & 25 & 25 \\
\hline Vacuum delivery & 2 & 2 \\
\hline Forceps delivery & 1 & 1 \\
\hline Total & $\mathbf{1 0 0}$ & $\mathbf{1 0 0}$ \\
\hline
\end{tabular}

In this study, 97 (97\%) of the patient required no surgical procedures other than caesarean section. One (1\%) patient required spleenectomy and $2(2 \%)$ needed internal iliac ligation to control the bleeding.

In this study, 9 (9\%) had caesarean section site oozing followed by 4 (4\%) patients had placental abruption, 2 (2\%) had episiotomy hematoma, $2(2 \%)$ had postpartum hemorrhage, and $1(1 \%)$ had hemo-peritoneum. None of patients had petechiae rashes, nose bleedings, gum bleeding, ecchymosis, gastrointestinal bleeding, intracranial bleeding or anesthetic complications like spinal or epidural hematoma (Figure 1).

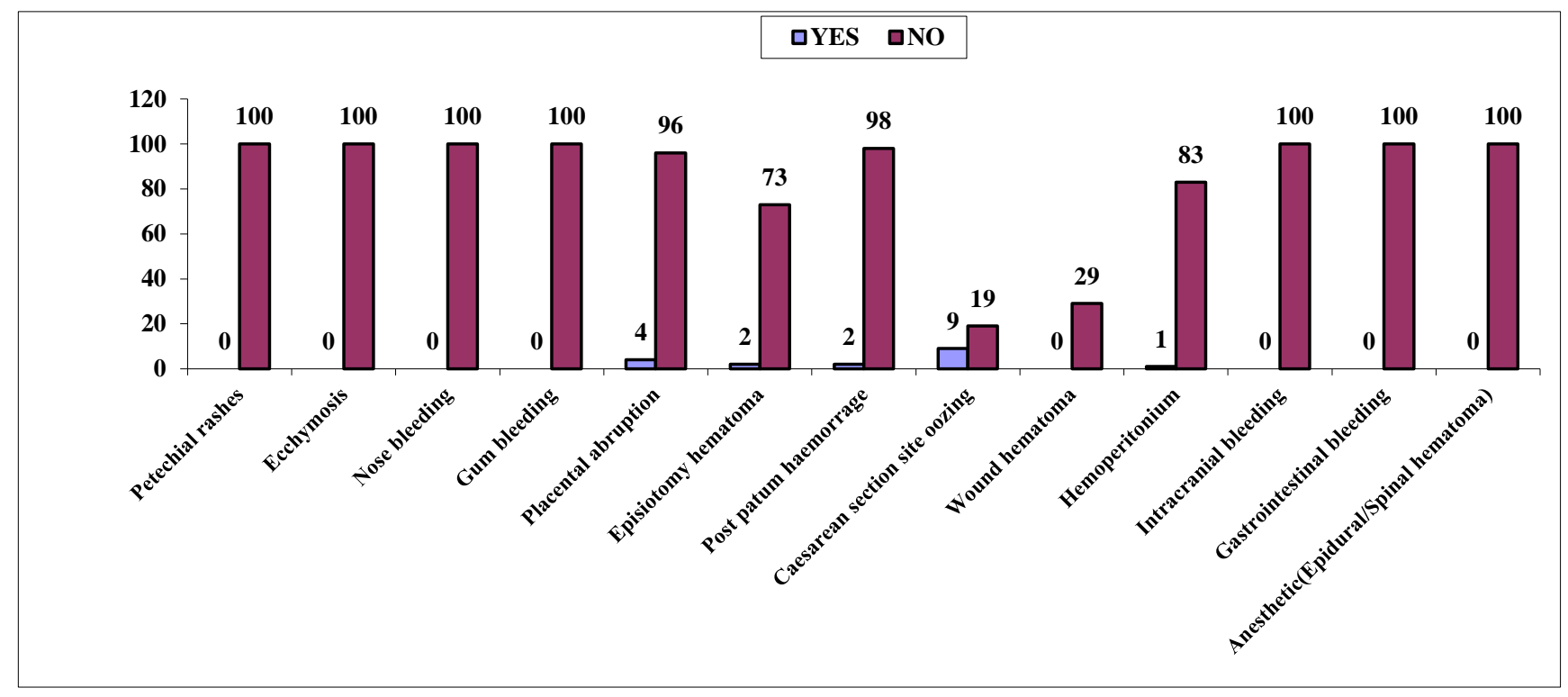

Figure 1: Distribution of study group depending on maternal complications.

On application of the Pearson's Chi-square test, on the maternal complications in the mothers with mild, moderate and severe thrombocytopenia, it was statistically significant (P-value of 0.038) (Table 7).

Out of total 100 cases, $73(73 \%)$ patients did not required any platelet transfusion and $27(27 \%)$ needed platelet transfusions (Table 8).
Majority of the patients ( $83 \%$ for PCV, $89 \%$ for CRYO, and $88 \%$ for FFP) not required any blood or blood products transfusions for the management of thrombocytopenia in pregnancy. Out of 100 patients 17 (17\%) needed packed cell volume (PCV), 11 (11\%) needed cryoprecipitate (Cryo), 12 (12\%) needed fresh frozen plasma (FFP) (Figure 2). 
Table 7: Statistical analysis of maternal complications in thrombocytopenia in pregnancy.

\begin{tabular}{|lllll|}
\hline $\begin{array}{l}\text { Chi square } \\
\text { test }\end{array}$ & Value & df & P-value & Association \\
\hline $\begin{array}{l}\text { Pearson chi } \\
\text { square }\end{array}$ & $\begin{array}{l}13.32 \\
\text { (a) }\end{array}$ & 6 & 0.038 & Significant \\
\hline
\end{tabular}

Table 8: Study group depending on need for platelet transfusion.

\begin{tabular}{|lll|}
\hline Platelets transfusion & $\mathbf{N}$ & $\%$ \\
\hline Yes & 27 & 27 \\
\hline No & 73 & 73 \\
\hline Total & $\mathbf{1 0 0}$ & $\mathbf{1 0 0}$ \\
\hline
\end{tabular}

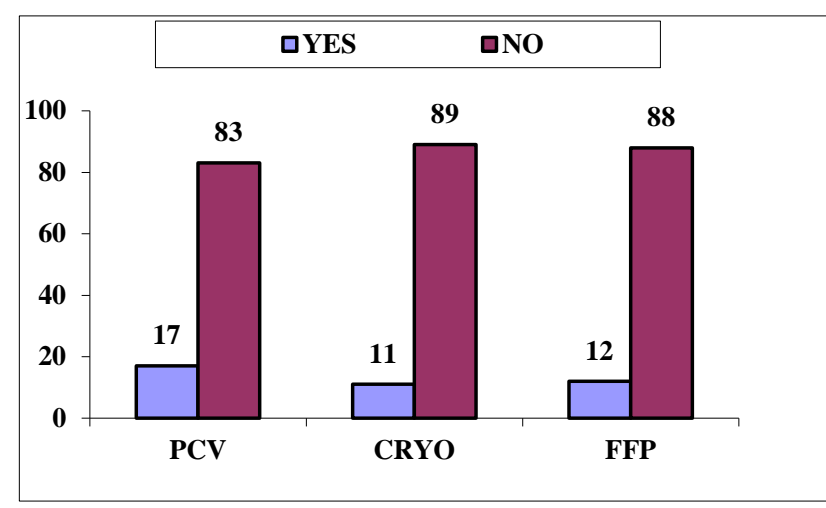

Figure 2: Distribution of study group depending on need for blood and blood product transfusion.

Table 9: Statistical analysis of need of blood and blood products in thrombocytopenia in pregnancy.

\begin{tabular}{|lllll|}
\hline $\begin{array}{l}\text { Chisquare } \\
\text { test }\end{array}$ & Value & Df & P-value & Association \\
\hline $\begin{array}{l}\text { Pearson chi } \\
\text { square }\end{array}$ & $\begin{array}{l}2.34 \\
\text { (a) }\end{array}$ & 4 & 0.67 & $\begin{array}{l}\text { Non- } \\
\text { significant }\end{array}$ \\
\hline
\end{tabular}

After applying Pearson's Chi square test on the above data there was no statistical significance in degree of thrombocytopenia and need for blood and blood product transfusion (P value 0.67) (Table 9).

Table 10: Distribution of study group depending on fetal and neonatal outcome.

\begin{tabular}{|lll|}
\hline Fetal and neonatal outcome & N & $\%$ \\
\hline MSB & 8 & 8 \\
\hline FSB & 3 & 3 \\
\hline NND & 2 & 2 \\
\hline Live birth & 87 & 87 \\
\hline Total & $\mathbf{1 0 0}$ & $\mathbf{1 0 0}$ \\
\hline
\end{tabular}

Out of 100 patients, only $6(6 \%)$ patients required medical intensive care unit (MICU) admission. There were $2(2 \%)$ maternal deaths reported in our study. One was due to complicated malaria in patient with Sjogren syndrome with renal tubular acidosis and other one was due to severe pre-eclampsia with DIC.

There were 2 neonatal deaths (NND), 3 fresh still births (FSB) and 8 macerated still births (MSB) out of 100 deliveries (Table 10).

Table 11: Distribution of study group depending thrombocytopenia in neonates.

\begin{tabular}{|lll|}
\hline Neonatal thrombocytopenia & N & $\%$ \\
\hline Yes & 2 & 2 \\
\hline No & 98 & 98 \\
\hline Total & 100 & 100 \\
\hline
\end{tabular}

Out of 100 patients, 19(19\%) of new-born babies of thrombocytopenic mother had required neonatal intensive care unit (NICU) admission.

Only $2(2 \%)$ neonates of thrombocytopenic mothers had thrombocytopenia (Table 11).

Only 1 neonate of thrombocytopenic mothers required platelet transfusion.

Both the thrombocytopenic neonates required IVIg injection. Dose was $1 \mathrm{~g} / \mathrm{kg}$. Total 2 doses were given for 2 consecutive days.

\section{DISCUSSION}

\section{Maternal age}

Mean maternal age in our study was 26.87 years (19-45 years) which is comparable to the study conducted by Janes SL et al, was 25.38 years (24-29 years) and Thanoon AM et al, which was 28.80 years (16-44 years). ${ }^{9-10}$

\section{Referral status}

In the present study, $50 \%$ of the patients were referred and $50 \%$ were registered to our institute. As our institute is a tertiary care centre about $50 \%$ of the patient with thrombocytopenia referred to us for better and prompt management.

Also, it has been widely accepted that standard antenatal care has immense values in the diagnosis of thrombocytopenia hence due to their registration $50 \%$ of the patient diagnosed as thrombocytopenia early and managed timely and promptly.

\section{Parity wise distribution of cases}

Majority of the patients in present study were multigravida $66(66 \%)$ followed by primigravida 34 $(34 \%)$. This was in contrast with the study conducted by 
Sarah L. Janes et al, which showed its prevalence was more in primigravida (70\%) and in multigravida (30\%). ${ }^{9}$

\section{Gestation age wise distribution}

In present study, we took only third trimester pregnant patients with thrombocytopenia. Out of 100 patients, 42 (42\%) patients presented at 30-36.6 weeks of gestation and $58(58 \%)$ patients diagnosed at $>37$ weeks of gestation. In majority $94(94 \%)$ of the patients, thrombocytopenia diagnosed in antepartum, followed by $6(6 \%)$ patients who presented with thrombocytopenia in intra-partum and none presented in postpartum period.

In another study conducted by Janes SL et al, done on thrombocytopenia in pregnancy which showed $22 \%$ in 24-28 weeks, $28 \%$ in $28-32$ weeks, $26 \%$ in $33-37$ weeks and $22 \%$ in $38-40$ weeks. $^{9}$

\section{Cause of thrombocytopenia in pregnancy wise distribution}

In present study, most common cause of thrombocytopenia in pregnancy was gestational thrombocytopenia in $25(25 \%)$ cases followed by preeclampsia 20 (20\%). Various other causes were dengue NS1 positive 14 (14\%), HELLP syndrome 8(8\%), ITP $6(6 \%)$, eclampsia $5(5 \%)$, complicated malaria $4(4 \%)$, liver diseases in pregnancy $7(7 \%)$ and $11(11 \%)$ cases due to other causes like DIC, aplastic anemia, chronic hypertension.

Sainio $S$ et al, also found out gestational thrombocytopenia $(81 \%)$ as most common cause followed by preeclampsia (16\%), ITP $(3 \%){ }^{1}$

Mcre $\mathrm{R}$ et al, in their study on thrombocytopenia in pregnancy in 1992 showed $71 \%$ were gestational, 6\% preeclampsia and 5\% were ITP which is comparable to our study. ${ }^{11}$

Bai ARG et al, in their study on thrombocytopenia in pregnancy found the incidence of thrombocytopenia in pregnancy as $7.6 \% .^{12}$

Parnas $\mathrm{M}$ et al, in their study on Moderate to severe thrombocytopenia in (platelet count below $100 \chi 109 / 1)$ pregnancy comparing 199 pregnant women found that the main causes of thrombocytopenia were gestational thrombocytopenia (GT) (59.3\%), immune thrombocytopenic purpura (ITP) $(11.05 \%)$, preeclampsia $(10.05 \%)$, and HELLP syndrome $(12.06 \%)$ which is comparable to our study. ${ }^{13}$

\section{Severity of thrombocytopenia}

In this study, majority $53(53 \%)$ of the patients had moderate thrombocytopenia $(0.5-1 \mathrm{lakh} / \mu \mathrm{L})$, followed by $33(33 \%)$ had mild thrombocytopenia $(1-1.5 \mathrm{lakh} / \mu \mathrm{L})$ and
$14(14 \%)$ patients had severe thrombocytopenia $(<0.5$ lakh/ $\mu \mathrm{L})$.

Asmaa M. Thanoon et al, found in their study that $63.5 \%$ had mild thrombocytopenia (100-149 x 109/L), 36.5\% had moderate thrombocytopenia (50-99 x109/L) while none had severe thrombocytopenia $(<50 \times 109 / \mathrm{L}) .{ }^{10}$

\section{Mean platelet count}

Mean platelet count in our study was $84.6 \times 109 / \mathrm{L}$.

Bai ARG et al, and Ajzenberg $\mathrm{N}$ et al found mean platelet count $135 \times 109 / \mathrm{L}$ and $69 \times 109 / \mathrm{L}$ in their studies respectively. ${ }^{12,14}$

\section{Mode of delivery}

In present study, 25 (25\%) patients required caesarean sections and 75 (75\%) delivered vaginally out of which 3 $(3 \%)$ required instrumental delivery.

In contrast to our study, Janes SL et al, studies on 50 eclampsia and preeclamptics pregnant patients complicated with thrombocytopenia found $58 \%$ patients needed caesarean section and $42 \%$ delivered vaginally. ${ }^{9}$

\section{Maternal complications}

In this study, $9(9 \%)$ had caesarean section site oozing followed by $4(4 \%)$ had placental abruption, 2 (2\%) had episiotomy hematoma, $2(2 \%)$ had postpartum hemorrhage $1(1 \%)$ had hemo-peritoneum. None had petechiae rashes, nose bleedings, gum bleeding, ecchymosis, gastrointestinal bleeding, intracranial bleeding or anesthetic complications like spinal or epidural hematoma. Only $6(6 \%)$ patients required medical intensive care unit (MICU) admission. There were 2 maternal deaths in this study. One was due to complicated malaria in patient with Sjogren syndrome with renal tubular acidosis and other one was due to severe pre-eclampsia with DIC. On application of the Pearson's Chi-square test, on the maternal complications in the mothers with mild, moderate and severe thrombocytopenia, it was statistically significant ( $\mathrm{P}$ value of 0.038$)$.

Majority of the patient $97(97 \%)$ required no surgical procedures other than caesarean section. One (1\%) patient required spleenectomy and $2(2 \%)$ needed internal iliac ligation to control the bleeding.

\section{Blood and blood products transfusion}

In this study, platelet transfusion was required in 27 (27\%) patients followed by PCV in 17 (17\%), FFP in 12 $(12 \%)$ and cryoprecipitate in $11(11 \%)$ patients. Majority of patients $73(73 \%)$ for platelet, $87(87 \%)$ for PCV, 88 $(88 \%)$ for FFP and $89(89 \%)$ for cryoprecipitate) did not require transfusion of blood or blood products. After 
applying Pearson's Chi square test on the above data there was no statistical significance in degree of thrombocytopenia and need for blood and blood product transfusion (p-value 0.67).

Study conducted by Ajzenberg $\mathrm{N}$ et al, showed $22 \%$ needed treatment for thrombocytopenia out of which only $2 \%$ needed platelet transfusion. ${ }^{14}$

\section{Neonatal outcome}

Out of total 100 patients, only 19 (19\%) of newborn babies of thrombocytopenic mother required neonatal intensive care unit (NICU) admission. There were 2 neonatal deaths (NND), 3 fresh still births (FSB) and 8 macerated still births (MSB) out of 100 deliveries.

\section{Neonatal thrombocytopenia}

In this study, only $2(2 \%)$ neonates of thrombocytopenic mothers had thrombocytopenia.

Sainio $\mathrm{S}$ et al, and Bai $\mathrm{ABG}$ et al, found neonatal thrombocytopenia in $2.1 \%$ and $4 \%$ cases respectively which was comparable to our study. ${ }^{12}$

In contrast to our study, Ajzenberg $\mathrm{N}$ et al, found neonatal thrombocytopenia in $38 \%$ in their study. ${ }^{14}$

\section{Neonatal platelet transfusion}

Both the thrombocytopenic neonates required IVIg injection. Dose given was $1 \mathrm{~g} / \mathrm{kg}$ Total 2.

doses were given for 2 consecutive days. 1 thrombocytopenic neonate required platelet transfusion as well.

In study conducted by Ajzenberg $\mathrm{N}$ et al, only 1 out of 24 thrombocytopenic neonates required treatment in form of oral steroids. ${ }^{14}$

\section{CONCLUSION}

Thrombocytopenia typically complicates the pregnancy. The overall incidence of thrombocytopenia in pregnancy is approximately $8-10 \%$. Although the cause of thrombocytopenia in pregnancy is not known in most, it can be pregnancy specific like gestational thrombocytopenia, pre-eclampsia, eclampsia, HELLP syndrome and pregnancy nonspecific like ITP, dengue, malaria, DIC, liver parenchymal diseases. Evidences of thrombocytopenia may begin early in pregnancy associated with pathophysiological changes that gains momentum across gestation and eventually becomes apparent as pregnancy advances. Most common cause is gestational thrombocytopenia with uneventful course in pregnancy with good maternal and neonatal outcomes. In most cases of mild to moderate thrombocytopenia, maternal and neonatal outcome is favorable with uneventful benign course without need of blood and blood products transfusion. Few severe cases of thrombocytopenia and those associated with medical or systematic cause leads to serious catastrophic lifethreatening events to mother, fetus and neonate. This emphasize need of early antenatal registration, routine antenatal checkups, increased surveillance in high risk cases, monitoring signs and symptoms and appropriate investigations which help in early diagnosis. Most of complications can be prevented with regular meticulous antenatal follow up and vigilant monitoring and prompt and appropriate treatment by multidisciplinary team of obstetrician, hematologist, anesthesiologist and neonatologist, physician.

Funding: No funding sources

Conflict of interest: None declared

Ethical approval: Not required

\section{REFERENCES}

1. Saino S, Kekomaki R, Riikonon S, Teramo $\mathrm{K}$. Maternal thrombocytopenia at term: a populationbased study. Acta obstet Gynecol Scand. 2000;79(9):744-9.

2. Boehlen F, Hohlfeld P, Extermann P, Perneger TV, de Moerloose Platelet count at term pregnancy: a reappraisal of the threshold. Obstet Gynecol. 2000;95(1):29-33.

3. Mc crae KR. Thrombocytopenia in pregnancy: differential diagnosis, pathogenesis, management. Blood Rev. 2003;17(1):7-14.

4. Bohlen F. Thrombocytopenia during pregnancy: Importance, diagnosis, management. Hamostaseol. 2006;26(10):72-4.

5. Sullivan CA, Martin JN, Jr Management of the obstetric patient with thrombocytopenia. Clin Obstet Gynecol. 1995;38:521-34.

6. Burrows RF, Kelton JG. Thrombocytopenia at delivery: a prospective survey of 6715 deliveries. Am J Obstet Gynecol. 1990;162:731-4.

7. Gernsheimer T, James AH, Stasi R. How I treat thrombocytopenia in pregnancy. Blood. 2013;121(1):38-47.

8. Richard F, Alexandre H. Thrombocytopenia in pregnancy, 2006. Available at: www.emedicine.medscape.com/article. Accessed on 15th January 2011.

9. Janes SL. Thrombocytopenia in pregnancy. Postgrad Med J. 1992;68:321-6.

10. Thanoon AM, Jalal SD. Thrombocytopenia in Iraqi pregnant women. J Fac Med Baghdad. 2011;53(2):171-4.

11. McCrae KR, Samuels P, Schreiber AD, Pregnancy associated thrombocytopenia: pathogenesis and management. Blood. 1992;80(11):2697-714.

12. Gari-Bai AR, Fachartz. Thrombocytopenia during pregnancy. Ann Saudi Med. 1998;18(2):135-9. 
13. Parnus M, Shriner E. Moderate to severe thrombocytopenia during pregnancy. Eur J Obstet Gynecol Reprod Book. 2006;128(1-2):163-8.

14. Ajzenberg N, Dreyfus M, Kaplan C, Yvart J, Weill B, Tchernia G. Pregnancy associated thrombocytopenia revisited: assessment and followup of 50 cases. Blood. 1998;92(12):4573-80.

Cite this article as: Kumari $\mathrm{P}$, Bhangale SV, Patil AN. Obstetric and neonatal outcomes of the pregnancies complicated with thrombocytopenia. Int J Reprod Contracept Obstet Gynecol 2019;8:427684. 